\title{
ENDOSCOPY
}

\section{Prediction of therapeutic failure after adrenaline injection plus heater probe treatment in patients with bleeding peptic ulcer}

\author{
S K H Wong, L-M Yu, J Y W Lau, Y-H Lam, A C W Chan, E K W Ng, J J Y Sung, \\ S C S Chung
}

Gut 2002;50:322-325

See end of article for authors' affiliations

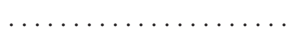

Correspondence to: S C S Chung, Chinese University of Hong Kong, Shatin, Hong Kong SAR, China;

sydneychung@cuhk.edu.hk

Accepted for publication 18 June 2001

\begin{abstract}
Background: Continued or recurrent bleeding after endoscopic treatment for bleeding ulcer is a major adverse prognostic factor. Identification of such ulcers may allow for alternate treatments.

Aim: To determine factors predicting treatment failure with combined adrenaline injection and heater probe thermocoagulation.

Methods: Consecutive patients with bleeding peptic ulcers who received endoscopic therapy between January 1995 and March 1998 were studied. Data on clinical presentation, endoscopic findings, and treatment outcomes were collected prospectively. Multiple logistic regression analysis was used to identify independent risk factors for treatment failure.

Results: During the study period, 3386 patients were admitted with bleeding peptic ulcers: 1144 (796 men, 348 women) with a mean age of 62.5 (SD 17.6) years required endoscopic treatment. There were 666 duodenal ulcers (58.2\%), 425 gastric ulcers (37.2\%), and 53 anastomotic ulcers (4.6\%). Initial haemostasis was successful in 1128 patients (98.6\%). Among them, $94(8.2 \%)$ rebled in a median time of 48 hours (range 3-480). Overall failure rate was $9.6 \%$. Mortality rate was 5\% (57) 1 144). Multiple logistic regression analysis revealed that hypotension (odds ratio (OR) $2.21,95 \%$ confidence interval (CI) 1.40-3.48), haemoglobin level less that $10 \mathrm{~g} / \mathrm{dl}$ (OR 1.87, 95\% Cl 1.18-2.96), fresh blood in the stomach (OR 2.15,95\% Cl 1.40-3.31), ulcer with active bleeding (OR 1.65, 95\% $\mathrm{Cl} 1.07-2.56)$, and large ulcers (OR $1.80,95 \% \mathrm{Cl} 1.15-2.83)$ were independent factors predicting rebleeding.
\end{abstract}

Conclusions: Larger ulcers with severe bleeding at presentation predict failure of endoscopic therapy.
B leeding peptic ulcer is a common and life threatening medical emergency. Endoscopic haemostasis has significantly improved the outcome of patients with bleeding peptic ulcers. ${ }^{1-3}$ While endoscopic therapy can stop bleeding in most bleeding ulcers, $10-20 \%$ of patients continue to bleed or rebleed after initial control. Recurrent bleeding remains the single most important adverse prognostic factor. ${ }^{4}$ Mortality in these patients increases substantially. Identification of such patients may allow for alternate treatment strategies to prevent recurrent bleeding.

In a randomised study, we demonstrated that adding heat probe thermocoagulation after adrenaline injection was more effective compared with adrenaline injection alone. ${ }^{5}$ In this prospective study, we sought to determine factors that may predict therapeutic failure after the combined treatment.

\section{PATIENTS AND METHODS}

The Prince of Wales Hospital is a teaching hospital that serves a catchment population of 1.2 million. All patients presenting with upper gastrointestinal bleeding are admitted under the joint care of medical and surgical gastroenterologists. All patients underwent endoscopy within 24 hours of admission. Patients who presented with fresh haematemesis or circulatory instability underwent emergency endoscopy after initial resuscitation. Twelve experienced endoscopists proficient at endoscopic treatment of bleeding peptic ulcers formed our gastrointestinal bleeding roster. Treatment procedures were performed by these endoscopists or training registrars under their supervision. Actively bleeding ulcers, ulcers with non-bleeding visible vessels (defined as protuberant discolourations) were treated. Clots were lifted by targeted irrigation with a heater probe or mechanically with the use of a mini-snare. Adrenaline (1:10 000 dilution) was injected in $0.5-1 \mathrm{ml}$ aliquots into and around the bleeding point. Active bleeding usually ceases allowing a clear view of the bleeding vessel after which tamponade is firmly appied using a $3.2 \mathrm{~mm}$ heat probe (CD-10Z; Olympus, Tokyo, Japan) using a dual channel endoscope (2T-10 or 2T-200; Olympus). Coagulation at $30 \mathrm{~J}$ is then activated. A continuous set of three pulses are applied to any one site. Successful treatment was defined by cessation of bleeding and flattening or "cavitation" of the bleeding point. After treatment, patients were returned to the surgical gastroenterology ward for monitoring. Haemoglobin level was monitored daily and blood transfusion was given to maintain a haemoglobin concentration of approximately $10 \mathrm{~g} / \mathrm{dl}$. A policy of early feeding was adopted and oral omeprazole (Losec; Astra, Sweden) with or without Helicobacter pylori eradication therapy were prescribed.

Permanent haemostasis was defined as successful initial haemostasis and absence of recurrent bleeding within the period of hospitalisation. Primary failure was defined as failure to stop bleeding during the index endoscopy and these patients underwent immediate surgery. Recurrent bleeding was defined by one of the following: fresh haematemesis, hypotension (systolic blood pressure $<90 \mathrm{~mm} \mathrm{Hg}$ ) with tachycardia (pulse $>110$ beat $/ \mathrm{min}$ ) or with melena, or a total transfusion requirement of greater than 4 units to maintain a haemoglobin level of approximately $10 \mathrm{~g} / \mathrm{dl}$ within 72 hours

Abbreviations: ROC, receiver operating characteristic. 
Table 1 Univariate analysis: clinical and endoscopic factors related to failure of dual endoscopic therapy

\begin{tabular}{|c|c|c|c|}
\hline & $\begin{array}{l}\text { Permanent } \\
\text { haemostasis } \\
(n=1034)\end{array}$ & $\begin{array}{l}\text { Failure } \\
(n=110)\end{array}$ & $\begin{array}{l}\text { Univariate } \\
\mathrm{p} \text { value }\end{array}$ \\
\hline \multicolumn{4}{|l|}{ Clinical variables } \\
\hline Age $(y)^{*}($ mean $(S D))$ & $62.1(17.7)$ & $65.8(16.0)$ & \multirow{2}{*}{$\begin{array}{l}0.036^{*} \\
0.235\end{array}$} \\
\hline Sex (male) & 714 (69.1) & $82 \quad(74.5)$ & \\
\hline Symptom-haematemesis* & 150 & $24 \quad(21.8)$ & $0.042 *$ \\
\hline Associated medical illness & $281 \quad(27.1)$ & $29 \quad(26.4)$ & 0.855 \\
\hline Ulcer history & 425 (41.1) & $41 \quad(37.3)$ & 0.119 \\
\hline $\mathrm{H} 2 \mathrm{~B} / \mathrm{PPI}$ & $65 \quad(6.3)$ & 8 (7.3) & 0.688 \\
\hline NSAID/aspirin & $323 \quad(31.2)$ & $26 \quad(23.6)$ & 0.105 \\
\hline Shock* (systolic BP $<100 \mathrm{~mm} \mathrm{Hg}$ ) & $147 \quad(14.2)$ & $35 \quad(31.8)$ & $<0.001$ * \\
\hline $\mathrm{Hb}$ level $(\mathrm{g} / \mathrm{dl})^{*}($ mean $(\mathrm{SD}))$ & $9.9(4.7)$ & $8.5(2.8)$ & $<0.001^{*}$ \\
\hline $\mathrm{Hb}$ level $<10 \mathrm{~g} / \mathrm{dl}^{*}$ & $565 \quad(54.8)$ & $80 \quad(74.1)$ & $<0.001^{*}$ \\
\hline \multicolumn{4}{|l|}{ Endoscopic findings } \\
\hline Ulcer size $\geqslant 2 \mathrm{~cm}$ & $208 \quad(20.1)$ & $36 \quad(32.7)$ & $0.002^{*}$ \\
\hline Active bleeding ulcer (Forrest grade I - spurter/oozing) & $516 \quad(49.9)$ & $71 \quad(64.5)$ & $0.003^{*}$ \\
\hline Fresh blood/clots in stomach* & $231 \quad(22.3)$ & $50 \quad(45.5)$ & $<0.001^{*}$ \\
\hline \multicolumn{4}{|l|}{ Ulcer types } \\
\hline Gastric ulcer & $380 \quad(36.5)$ & $45 \quad(40.9)$ & \multirow[t]{3}{*}{$0.029 *$} \\
\hline Duodenal ulcer & $611 \quad(59.1)$ & $55 \quad(50.0)$ & \\
\hline Stomal ulcer * & $43(4.2)$ & 10 (9.1) & \\
\hline \multicolumn{4}{|c|}{$\begin{array}{l}\text { Values are number }(\%) \text { unless otherwise stated. } \\
\mathrm{H} 2 \mathrm{~B}, \mathrm{H} 2 \text { blockers; PPI, proton pump inhibitors; NSAID, non-steroidal anti-inflammatory drugs. } \\
\text { * Significant factor. }\end{array}$} \\
\hline
\end{tabular}

after endoscopic treatment. No comparative trial of endoscopic treatments was in progress during the study period. Patients who developed recurrent bleeding after initial endoscopic control were then recruited into a randomised study comparing emergency surgery and endoscopic retreatment. ${ }^{6} \mathrm{~A}$ uniform treatment protocol ensured that patients enrolled into this subsequent trial had been treated in an identical manner prior to their trial entry.

Patient baseline characteristics and details of endoscopic treatment were recorded by endoscopists at the end of each therapeutic procedure. Our fulltime research nurses entered data daily in our gastrointestinal bleeding registry and followed the patient's hospital course and outcome until discharge or death. This was cross checked against a computerised hospital record on patient discharges or deaths. Data were analysed using the S-Plus (MathSoft Inc, Seattle, Washington, USA). Factors predicting therapeutic failure were first identified using univariate analysis. Those with $\mathrm{p}$ values less than 0.25 were then entered into a stepwise multiple logistic regression. Significant independent factors were considered when $\mathrm{p}<0.05$.

The predictive ability of the final prognostic model was assessed by means of the area under the receiver operating characteristic (ROC) curve ${ }^{7}$ and was validated using the bootstrapping technique to correct for possible bias due to overestimation of the predictive performance of the final model. ${ }^{8}$ An area under the ROC curve value of 0.5 indicates no predictive power whereas a value of 1.0 indicates excellent prediction.

In recent years there has been concern regarding how well a prognostic model works in practice and it is widely recommended that they need to be validated. The bootstrapping technique is a method being used increasingly in the context of internal validation of a prognostic model. The method involves selecting a random sample, the bootstrap sample, of 1144 observations from the original dataset with replacement into the final model. A stepwise logistic regression model is then derived from this bootstrap sample, and the predictive performance is evaluated on the bootstrap sample, $\mathrm{ROC}_{\text {boot }}$ and on the original dataset, $\mathrm{ROC}_{\text {org }}$. The difference between the two predictive performances (that is, $\mathrm{ROC}_{\text {boot }}-\mathrm{ROC}_{\text {org }}$ ) yields a bias statistic. This process was repeated 500 times and an average bias was calculated over the 500 bootstrap samples, $\mathrm{ROC}_{\text {bias }}$. The bootstrap corrected performance of the prognostic model was calculated by subtracting $\mathrm{ROC}_{\text {bias }}$ from the area under the ROC derived from the original stepwise logistic regression model.

\section{RESULTS}

During the study period there were 3386 patients with bleeding peptic ulcers. Of these, 1144 (796 men, 348 women) required endoscopic treatment. Mean age was 62.5 (SD 17.6) years. A total of 466 patients had a previous history of peptic ulcer disease (40.7\%) and 349 (30.5\%) were receiving non-steroidal anti-inflammatory drugs or aspirin. There were 425 gastric ulcers $(37.2 \%), 666$ (58.2\%) duodenal ulcers, and $53(4.6 \%)$ anastomotic ulcers.

Therapy could not be completed in 16 patients ( $1.4 \%$ ) due to torrential bleeding that prevented adequate visualisation of the ulcers and all were treated by emergency surgical haemostasis. Successful initial haemostasis was achieved in 1128 patients $(98.6 \%)$ and permanent haemostasis was achieved in $1034(90.4 \%)$. Ninety four patients $(8.2 \%)$ developed inhospital rebleeding at a mean time of 60 hours (SD 68) after the index endoscopy.

Heater probe related perforations occurred in 14 patients ( $1.4 \%)$ (three after repeat endoscopic therapy) and all underwent emergency surgery. In those in whom permanent haemostasis was achieved, 3.8\% (39/1034) died from their comorbid illnesses. Of 110 patients in whom endoscopic haemostasis failed, mortality was $16.4 \%$ (18 deaths). Overall mortality was $5.0 \%$ (57/1 144 patients).

In a univariate analysis, the clinical variables age $(p=0.036)$, haemoglobin concentration at presentation $(\mathrm{p}<0.001)$, hypotension $(\mathrm{p}<0.001)$, and fresh haematemesis $(p=0.042)$, and four endoscopic variables (presence of fresh blood or clots in the stomach $(\mathrm{p}<0.001)$, ulcers with active bleeding (Forrest's grade I; $\mathrm{p}<0.001$ ), ulcer size greater than 2 $\mathrm{cm}(\mathrm{p}=0.002)$, and anastomotic ulcers $(\mathrm{p}=0.029))$ were significantly related to therapeutic failure (tables 1, 2). Further analysis using a multiple stepwise logistic regression model showed that hypotension $(\mathrm{p}<0.001$; odds ratio $(\mathrm{OR})$ $2.21,95 \%$ confidence interval (CI) 1.40-3.48), haemoglobin level less that $10 \mathrm{~g} / \mathrm{dl}(\mathrm{p}=0.007$; OR $1.87,95 \%$ CI $1.18-2.96)$, 
Table 2 Univariate analysis: ulcer size and location in gastric and duodenal ulcers

\begin{tabular}{lcll}
\hline & $\begin{array}{l}\text { Permanent } \\
\text { haemostasis }\end{array}$ & Failure & $\begin{array}{l}\text { Univariate } \\
\text { p value }\end{array}$ \\
\hline Gastric ulcers $(n=425)$ & 380 & 45 & \\
Ulcer $\geqslant 2 \mathrm{~cm}(n=156)$ & $133(35.0)$ & $23(51.1)$ & $0.034^{*}$ \\
Location & & & \\
$\quad$ Lesser curve & $59(15.5)$ & $11(24.4)$ & \\
Angular incisura & $102(26.8)$ & $12(26.7)$ & \\
Antrum & $195(51.3)$ & $18(40.0)$ & \\
$\quad$ Other & $24(6.3)$ & $4(8.9)$ & 0.337 \\
Duodenal ulcers ( $n=666)$ & 611 & 55 & \\
Ulcer $\geqslant 2 \mathrm{~cm}(n=83)$ & $71(11.6)$ & $12(21.8)$ & $0.028^{*}$ \\
Location & & & \\
Anterior wall & $391(64.0)$ & $32(58.2)$ & \\
Posterior wall & $45(7.4)$ & $4(7.3)$ & \\
$\quad$ Superior wall & $52(8.5)$ & $9(16.4)$ & \\
Inferior wall & $74(12.1)$ & $3(5.5)$ & \\
$\quad$ Other & $49(8.0)$ & $7(12.7)$ & 0.140 \\
\hline
\end{tabular}

Table 3 Risk factors predicting therapeutic failure of endoscopic haemostasis from stepwise logistic regression

\begin{tabular}{lll}
\hline & Odds ratio $(95 \% \mathrm{Cl})$ & $\mathrm{p}$ Value \\
\hline Haemoglobin level $<10 \mathrm{~g} / \mathrm{dl}$ & $1.87(1.18-2.96)$ & 0.007 \\
Ulcer $\geqslant 2 \mathrm{~cm}$ & $1.80(1.15-2.83)$ & 0.010 \\
Shock & $2.21(1.40-3.48)$ & $<0.001$ \\
Fresh blood in stomach & $2.15(1.40-3.31)$ & $<0.001$ \\
Active bleeding & $1.65(1.07-2.56)$ & 0.025 \\
\hline
\end{tabular}

$95 \% \mathrm{Cl}, 95 \%$ confidence interval.

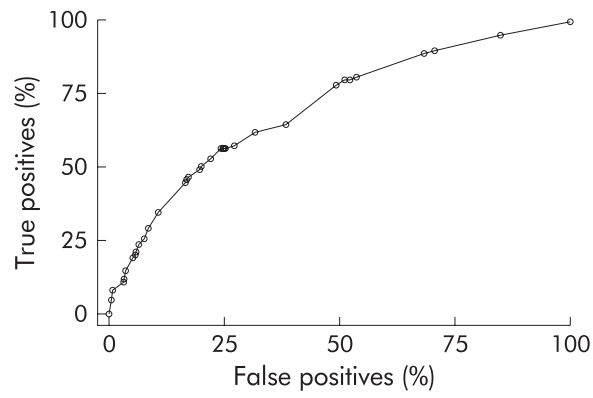

Figure 1 Receiver operating characteristic (ROC) curve for prediction of therapeutic failure.

fresh blood in the stomach $(\mathrm{p}<0.001$; OR $2.15,95 \%$ CI $1.40-3.31)$, ulcer with active bleeding $(p=0.025$; OR $1.65,95 \%$ CI 1.07-2.56), and large ulcers $\geqslant 2 \mathrm{~cm}(\mathrm{p}=0.010$; OR $1.80,95 \%$ CI 1.15-2.83) were found to be independent variables predicting therapeutic failure (table 3 ). The risk of failure increased twofold with each additional risk factor. The area under the ROC curve of the logistic regression model was $70.6 \%$ (fig 1 ) and the corrected area of the ROC curve from 500 bootstrap samples was $67.5 \%$, which suggested that the original predictive performance was overestimated by approximately $3 \%$.

\section{DISCUSSION}

In about $80 \%$ of patients with bleeding peptic ulcers, bleeding stops spontaneously. Endoscopic intervention is targeted at those bleeding at endoscopy or at risk of developing further bleeding. The National Institutes of Health consensus conference recommended that only ulcers with active bleeding or visible vessels should be treated endoscopically. ${ }^{1}$ Recent evidence indicates that patients with ulcer of an adherent clot may also constitute a high risk group. ${ }^{9}$ Various modalities of endoscopic therapies have been proved to reduce recurrent bleeding, the need for surgery, and mortality (on metaanalyses ). In our institution, we combine the use of adrenaline injection and thermocoagulation by heater probe. Preinjection with diluted adrenaline in the vicinity of the bleeding stops the bleeding, allowing a clear view, and accurate and firm tamponade. In our series, endoscopic adrenaline injection with heater probe treatment achieved permanent haemostasis in $90.4 \%$ of patients with a mortality rate of $5 \%$.

Our cohort of patients was younger than those of contemporary series. The National UK Audit conducted in 1993 was a population based study consisting of 4185 patients collected over a four month period. ${ }^{10}$ Their mean age was 66 years compared with 63 years in our series. It is well documented that old age is associated with increased mortality. Elderly patients often succumb to their concomitant illnesses rather than the bleeding itself. While old age predicts mortality, it does not predict failure of endoscopic therapy in most series. In a large series of unselected patients, Choudari and colleagues ${ }^{11}$ found no differences in the outcome of patients in different age groups ( $<60,61-74$, or $>75$ years) treated endoscopically. The authors suggested that age did not influence the response to or death after endoscopic treatment.

Several studies have defined factors that predict failure before endoscopic therapy ${ }^{12}{ }^{13}$ or after different treatment regimens. ${ }^{14-18}$ These factors were related to high risk ulcers (ulcer size/bleeding stigmata/position) with signs of massive bleeding (hypotension/ haematemesis/low haemoglobin level) or to patient characteristics (age/comorbidities/non-steroidal anti-inflammatory drug user). Similar factors were reported as significant in predicting rebleeding. ${ }^{12-18}$ Of the factors evaluated in these studies, one of the most consistent predictors of rebleeding was the position of the ulcer at the posterior duodenal bulb. This would seem logical as larger ulcers in this location would erode into branches of the gastroduodenal artery complex. This factor however was not significant in our analysis. This may be attributed to the unreliability of reporting ulcer location at the duodenal bulb at endoscopy. ${ }^{19}$ From our analysis, the principal determinants for recurrent bleeding appeared to be ulcer related while mortality was more related to rebleeding and patient age. ${ }^{10}$ Endoscopic therapy was most likely to fail for larger ulcers with rapid bleeding manifested by hypotension and low haemoglobin level.

Our prognostic model should ideally be validated prospectively in another cohort of patients. We choose to use the bootstrapping technique for internal validation of the final model. The corrected area of the ROC was $67.5 \%$, indicating fair predictive performance.

Heater probe related perforation occurred in $1.4 \%$ of our patients. This value is in keeping with those from other series. Zuccaro $^{20}$ summarised series using thermocoagulation and found a similar perforation rate of $1 \%$. In our experience, perforation often occurs at the thinner anterior duodenal wall. In the clinical setting, it is often difficult to distinguish a perforation from transmural thermal injury related to heater probe treatment from a sealed perforation reopened by gas insufflation during endoscopy. Larger chronic ulcers often involve the full thickness of the bowel wall. Their ulcer craters are technically outside the bowel wall. Our heater probe setting and technique have been reported by Johnston and colleagues ${ }^{21}$ based on experimental findings.

There is little controversy concerning the management course of patients with actively bleeding ulcers that fail to stop at the index endoscopy. Most would agree that these patients should undergo surgical treatment. The preferred line of management of ulcer haemorrhage after endoscopic haemostasis is not yet defined. Variables identified in this and other reports enable us to define high risk patients. Early elective surgery in these patients seems logical as mortality from elective surgery is likely to be substantially lower than that from 
emergency surgery. There are however few data in the literature to support such an approach. The role of second look endoscopy is unclear. Published studies on the use of routine second look endoscopy consist of inadequate patient numbers. ${ }^{22-24}$ The difference is likely to be marginal. With more effective index therapy, the gain from routine second look endoscopy would be evener smaller, and significant proportions of patients are likely to undergo unnecessary endoscopies.

In our series, heat probe related perforation during initial endoscopic haemostasis was approximately $1 \%$ but in our randomised study comparing endoscopic retreatment with surgery in rebleeding patients ${ }^{6}$ perforations from repeated heater probe use occurred in $2 / 44$ patients $(4.5 \%)$ and both were duodenal ulcers in the anterior wall. Contact thermal devices should be used with great caution. For this reason and because of its unproved benefit, we do not advocate routine second look endoscopy. It would seem more logical to be selective in offering repeat endoscopy. In a randomised study consisting of a smaller number of patients, Saeed and colleagues $^{25}$ adopted an approach of scheduled retreatment to high risk patients based on a composite clinical and endoscopic score and demonstrated a significant benefit in the prevention of rebleeding. In a randomised study comparing endoscopic retreatment with surgery in rebleeding patients from this same cohort, second look and retreatment at the time of recurrent bleeding caused haemostasis in approximately $75 \%$ of patients. Outcomes in both groups of patients were similar. A regression analysis indicated that ulcers greater than $2 \mathrm{~cm}$ and hypotension at recurrent bleeding were independent factors predicting retreatment failure. ${ }^{5}$ One could argue that these patients could be better served if they had undergone elective surgery to forestall rebleeding. Recently, we demonstrated that after initial endoscopy to control bleeding ulcers, high dose infusion of proton pump inhibitors substantially reduced recurrent bleeding and improved patient outcome. ${ }^{26}$ With a low rebleeding rate of about $5 \%$ and only approximately $10 \%$ in ulcers greater than 2 $\mathrm{cm}$ in size in patients on maximal acid reduction, we feel that this may represent the best treatment strategy after initial endoscopic control.

\section{ACKNOWLEDGEMENTS}

We thank Bing-Yee Suen, BSc, RN, Man-yee Yung, RN, and Suki Yu for technical and secretarial assistance.

\section{Authors' affiliations \\ S K H Wong, J Y W Lau, Y-H Lam, A C W Chan, E K W Ng, S C S \\ Chung, Department of Surgery, Chinese University of Hong Kong, Prince of Wales Hospital, Shatin, Hong Kong SAR, China \\ L-M Yu, Centre for Clinical Trials and Epidemiological Research, Chinese University of Hong Kong, Prince of Wales Hospital, Shatin, Hong Kong SAR, China \\ J J Y Sung, Department of Medicine and Therapeutics, Chinese University of Hong Kong, Prince of Wales Hospital, Shatin, Hong Kong SAR, China \\ REFERENCES \\ 1 NIH Consensus Conference. Therapeutic endoscopy and bleeding ulcers. JAMA 1989;262:369-72.}

2 Cook DJ, Guyatt GH, Salena BJ, et al. Endoscopic therapy for acute nonvariceal upper gastrointestinal hemorrhage. A meta-analysis. Gastroenterology 1992;102:139-48.

3 Sugawa C, Joseph AL. Endoscopic interventional management of bleeding duodenal and gastric ulcers. Surg Clin North Am 1992;72:317-24.

4 Jones AF. Haematemesis and melaena: With special reference to causation and to the factors influencing the mortality from bleeding peptic ulcers. Gastroenterology 1956:30: 166-90.

5 Chung SCS, Lau JYW, Sung JJY, et al. A randomized comparison between adrenaline injection alone and adrenaline injection plus heat probe treatment for actively bleeding peptic ulcers. BM 1997;314:1307-1 1.

6 Lau JY, Sung JJ, Lam YH, et al. Endoscopic retreatment compared with surgery in patients with recurrent bleeding after initial endoscopic control of bleeding ulcers. N Engl J Med 1999;340:751-6.

7 Hanley JA, McNeil BJ. The meaning and use of the area under a receiver operating characteristic (ROC) curve. Radiology 1982;143:29-36.

8 Harrell FE Jr, Lee KL, Mark DB. Multivariable prognostic models: Issues in developing models, evaluating assumptions and adequacy, and measuring and reducing errors. Stat Med 1996;15:361-87.

9 Ulrich CD, Gostout CJ, Balm RK. Prognostic importance of the densely adherent clot in bleeding ulcer disease (PUD). A 4-year retrospective review of the Mayo clinic experience. Gastrointest Endosc 1994;40:89.

10 Rockall TA, Logan RFA, Devlin HB, et al. Incidence of and mortality from acute upper gastrointestinal hemorrhage in the United Kingdom. BM 1995;311:222-6.

11 Choudari CP, Elton EA, Palmer KR. Age-related mortality in patients treated endoscopically for bleeding peptic ulcer. Gastrointest Endosc 1995:41:557-60

12 Jaramillo JL, Galvez C, Carmona C, et al. Predication of further hemorrhage in bleeding peptic ulcer. Am J Gastroenterol 1994;89:2135-8.

13 Branicki FJ, Coleman SY, Fok PJ, et al. Bleeding peptic ulcer: A prospective evaluation of risk factors for rebleeding and mortality. World J Surg 1990;14:262-70.

14 Saeed ZA, Winchester CB, Michaletz PA, et al. A scoring system to predict rebleeding after endoscopic therapy of non-variceal upper gastrointestinal hemorrhage, with a comparison of heat probe and ethanol injection. Am J Gastroenterol 1993;88: 1842-9.

15 Brullet E, Calvet X, Campo R, et al. Factors predicting failure of endoscopic injection therapy in bleeding duodenal ulcer. Gastrointest Endosc 1996:43:111-16.

16 Brullet E, Campo R, Calvet X, et al. Factors related to the failure of endoscopic injection therapy for bleeding gastric ulcer. Gut 1996;39: 155-8.

17 Villanueva C, Balanzo J, Espinos JC, et al. Prediction of therapeutic failure in patients with bleeding peptic ulcer treated with endoscopic injection. Dig Dis Sci 1993;38:2062-70.

18 Park KG, Steele RJ, Mollison J, et al. Prediction of recurrent bleeding after endoscopic haemostasis in non-variceal upper gastrointestinal haemorrhage. Br J Surg 1994;81:1465-8.

19 Straker RJ, Bienvenu JC, Nord HJ. Endoscopic orientation with the duodenal bulb. Endoscopy 1992;24:266-7.

20 Zuccaro G Jr. Bleeding peptic ulcer: pathogenesis and endoscopic therapy. Gastrointest Clin North Am 1993;22:737-50

21 Johnston JH, Jensen DM, Auth D. Experimental comparison of endoscopic yttrium-aluminum-garnet laser, electrosurgery, and heater probe for canine gut arterial coagulation. Importance of compression and avoidance of erosion. Gastroenterology 1987;92:1101-8.

22 Villanueva C, Balanzo J, Torras $X$, et al. Value of a second look endoscopy after injection therapy for bleeding peptic ulcer: a prospective and randomized trial. Gastrointest Endosc 1994:40:34-9.

23 Messmann H, Schaller P, Andus T, et al. Effect of programmed endoscopic follow-up examinations on the rebleeding rate of gastric or duodenal peptic ulcers treated by injection therapy: a prospective, randomized controlled trial. Endoscopy 1998:30:583-9.

24 Saeed ZA. Second thoughts about second-look endoscopy for ulcer bleeding? Endoscopy 1998;30:650-1.

25 Saeed ZA, Cole RA, Ramirez FC, et al. Endoscopic retreatment after successful initial hemostasis prevents ulcer rebleeding: a prospective randomized trial. Endoscopy 1996:28:288-94.

26 Lau JYW, Sung JYY, Lee KKC, et al. Effect of intravenous omeprazole on recurrent bleeding after endoscopic treatment of bleeding peptic ulcers. N Engl J Med 2000;343:310-16. 